Journal of Patient-Centered

8-15-2016

\title{
Complexity and Chaos in Surgical Start Times
}

Dennis J. Baumgardner

Follow this and additional works at: https://aah.org/jpcrr

Part of the Health and Medical Administration Commons, and the Surgical Procedures, Operative Commons

\section{Recommended Citation}

Baumgardner DJ. Complexity and chaos in surgical start times. J Patient Cent Res Rev. 2016;3:121-2. doi: 10.17294/2330-0698.1361

Published quarterly by Midwest-based health system Advocate Aurora Health and indexed in PubMed Central, the Journal of Patient-Centered Research and Reviews (JPCRR) is an open access, peer-reviewed medical journal focused on disseminating scholarly works devoted to improving patient-centered care practices, health outcomes, and the patient experience. 


\title{
Complexity and Chaos in Surgical Start Times
}

\author{
Dennis J. Baumgardner, MD | Message from the Editor-in-Chief \\ Department of Family Medicine, Aurora University of Wisconsin Medical Group, Aurora Health Care, Milwaukee, WI
}

In this issue of the Journal of Patient-Centered Research and Reviews, Cox Bauer et al. provide an elegant and interesting initial foray into the causes for delay of first-case operating room start times. ${ }^{1}$ Among the study's main findings were that $88 \%$ of first-ofthe-day scheduled surgical cases were delayed, and despite late arrival of the patient to the hospital $65 \%$ of the time, almost $60 \%$ of delayed cases had no listed reason for the delay. A number of potential predictor variables were explored for inclusion in fixed-effects logistic regression models, and key time intervals were investigated. Further documentation and study of the events leading up to surgical start times, along with implementation of Plan-Do-Study-Act cycles, were suggested to tackle this vexing problem.

Certainly, one would suspect (as did the authors) that inadequate or nonstandardized documentation may explain the seemingly high percentage of missing listed explanations for delay as well as the frequent mismatch between the "late arrival" field and cause of delay. I would submit, however, that the authors may well have uncovered an explanation for these delays: in essence, that there is no single or easily described reason.

Here is where complexity science, ${ }^{\text {cf.2 }}$ which has been described as "the study of intraconnected natural systems," 3 and chaos theory, ${ }^{\text {cf. } 4}$ the study of nonlinear dynamics, come in to play. Medical organizations and their processes are complex, dynamic, potentially fragile systems that often grow more complex over time. ${ }^{5}$ Properties characterizing such iterative systems of interacting parts include "self-organization, nonlinear adaptation, internal diversity and distributed control." 3 Furthermore, people (themselves complex interactive

Correspondence: Dennis J. Baumgardner, MD, Aurora Sinai Medical Center, 1020 N. 12th Street, \#4180, Milwaukee, WI, 53233, T: 414-219-5191, F: 414-219-3116, Email: dennis.baumgardner@aurora.org dynamic systems $)^{6}$ and processes increasingly rely on technology, which in turn is built of interacting components ("coupled links") that have become increasingly complex. $^{7}$ Thus, health care teams are "collections of individual agents with freedom to act in ways that are not always predictable,

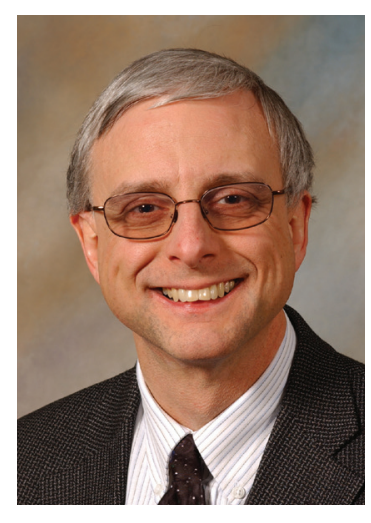
and whose actions are interconnected so that one agent's actions changes the context for other agents." "As nursing informatics and administration professor Thomas Clancy warns, "be prepared for the unexpected."7

One element of chaos theory that particularly portends difficulty in reliable prediction of, say, surgical start times in a complex dynamic system, is the so-called butterfly effect, i.e. extreme dependence on initial conditions. ${ }^{2,4}$ This is the phenomenon in which a minor perturbation in one location can a cause a major change downstream., ${ }^{4,6}$ Originally discovered by the meteorologist Edward Lorenz on a supercomputer in the early $1960 \mathrm{~s},{ }^{9}$ the concept is that a butterfly flying in an alternative direction can cause a major change in weather a few days later at a location a thousand miles away.,6

For this subject, take a hypothetical example of a young woman on her way to her early morning elective surgery. A crying toddler begging her not to leave combined with an overflowing sink delays her departure from the house by 15 minutes. While this action prevents her from being hit by an intoxicated driver head-on had she left on time, the ensuing traffic back-up brings her to the hospital's valet parking 25 minutes later than intended. Throw in one of the parking attendants calling in sick, and she arrives at the hospital check-in desk 35 minutes late. This line is momentarily stalled by a coworker asking computer advice from the receptionist delaying the woman's arrival to the preoperative holding area. 
In the meantime, three patients for later surgeries have already arrived and are being processed ahead of her, further increasing the delay (you get the idea). This description, of course, just deals with the patient's timeline to the preoperative holding area. Certainly, shortly after arrival in the holding area, the computer network could have gone down for several minutes, one of the holding rooms may have been contaminated and therefore unavailable, and multiple other problems in this interconnected process could have arisen. Thus, a number of problems unrelated to the patient's modestly late departure from home may have resulted in the 45-minutes-late start time for her particular procedure. Indeed the patient was late, but was it possible to pinpoint any one factor as the cause?

System complexity and its underlying science often make it difficult to "diagnose and treat" system problems such as delayed surgical start times. In addition, because of another principle of chaos theory, self-similarity on multiple scales, ${ }^{4}$ a whole systems change may be necessary to effect change rather than a focus on a couple of departments or processes. ${ }^{10}$ In fact, because of interdependencies, changes in one part of the system may have "counterintuitive consequences" on other parts..$^{10}$

But all is not hopeless. Plsek and Greenhalgh have noted, "A complex system can adapt its behavior over time," by not focusing completely on traditional linear, reductionist thinking (e.g. "reduce and resolve" approaches focused on a single department). ${ }^{8}$ Accepting unpredictability and building more flexibility and crosscommunication into multiple interacting departments may achieve better results. ${ }^{8}, 11$ Simple things such as cross-training and avoiding undue redundancy may well have an impact. Use of the electronic medical record should address the latter, for example, by maintaining clear documentation that avoids having patients asked the same questions by multiple persons along the way. ${ }^{5}$ Some redundancy increases patient safety; too much is inefficient. System change is often a matter of will.

Can scientific theories or mathematical models help solve problems such as surgical wait times? Recent use of queueing theory simulations (of which I, admittedly, have no knowledge or experience) in emergency and recovery room wait times, intensive care unit bed flow, outpatient cycle times and other health care management issues is of interest. ${ }^{12-16}$ The advantage of queueing models is they are relatively simple, quick and applicable to systems with unpredictable behavior. ${ }^{13}$ While likely better for supply-and-demand situations and less applicable overall to complex, dynamic systems, ${ }^{13-16}$ they may nonetheless be useful to guide change in single or closely related departments.

Perhaps selected use of such simulation models combined with a whole systems approach, patient, clinician and staff coaching, dedication, determination and common sense - can lead to reductions in firstcase surgical start delays.

\section{References}

1. Cox Bauer C, Greer DM, Vander Wyst KB, Kamelle SA. Firstcase operating room delays: patterns across urban hospitals within a single health care system. J Patient Cent Res Rev. 2016;3:125-35.

2. Casti JL. Complexification: Explaining a Paradoxical World Through the Science of Surprise. New York: Harper Collins, 1994.

3. Petzinger T. Complexity made simple. Interview by David Ollier Weber. Hops Health Netw. 2004;78(5):54-6, 59, 2.

4. Gleick J. Chaos: Making a New Science. New York: Viking, 1987.

5. Clancy TR. Complexity, flow, and antifragile healthcare systems: implications for nurse executives. J Nurs Admin. 2015;45:188-91. CrossRef

6. Wilson T, Holt T, Greenhalgh T. Complexity science: complexity and clinical care. BMJ. 2001;323:685-8. CrossRef

7. Clancy TR. Technology and complexity: trouble brewing? J Nurs Admin. 2010;40:247-9. CrossRef

8. Plsek PE, Greenhalgh T. Complexity science: the challenge of complexity in health care. BMJ. 2001;323:625-8. CrossRef

9. Lorenz EN. Deterministic nonperiodic flow. $J$ Atmos Sci. 1963;20:130-41. CrossRef

10. Dattée B, Barlow J. Complexity and whole-system change programmes. J Health Serv Res Policy. 2010;15 Suppl 2:19-25. CrossRef

11. Waring J, McDonald R, Harrison S. Safety and complexity: inter-departmental relationships as a threat to patient safety in the operating department. J Health Organ Manag. 2006;20: 227-42. CrossRef

12. Morton A, Bevan G. What's in a wait? Contrasting management science and economic perspectives on waiting for emergency care. Health Policy. 2008;85:207-17. CrossRef

13. Schoenmeyr T, Dunn PF, Gamarnik D, et al. A model for understanding the impacts of demand and capacity on waiting time to enter a congested recovery room. Anesthesiology. 2009;110:1293-304. CrossRef

14. Mathews KS, Long EF. A conceptual framework for improving critical care patient flow and bed use. Ann Am Thorac Soc. 2015;12:886-94. CrossRef

15. Jiang L, Giachetti RE. A queueing network model to analyze the impact of parallelization of care on patient cycle time. Health Care Manag Sci. 2008;11:248-61. CrossRef

16. Palvannan RK, Teow KL. Queueing for healthcare. J Med Syst. 2012:36:541-7. CrossRef

(C) 2016 Aurora Health Care, Inc. 